\title{
SURVEY OF PATIENTS' ATTITUDE ABOUT ANAESTHESIA AND ANAESTHESIOLOGIST - A PRELIMINARY EVALUATION IN A RURAL HOSPITAL OF NORTH BENGAL
}

\author{
Susanta Sarkar1, Mohanchandra Mandal2, Piyali Chakrabarti³, Dipanjan Bagchi', Suchitra Pal ${ }^{5}$ \\ ${ }^{1}$ Associate Professor, Department of Anaesthesiology, North Bengal Medical College, Sushrutanagar, Darjeeling, West Bengal. \\ ${ }^{2}$ Associate Professor, Department of Anaesthesiology, North Bengal Medical College. \\ ${ }^{3}$ Postgraduate Trainee, Department of Physiology, North Bengal Medical College. \\ ${ }^{4}$ Consultant Anaesthesiologist, Howrah District Hospital, Howrah, West Bengal. \\ ${ }^{5}$ Nursing Sister, Department of Psychiatry, Central Hospital, SE Railway, Kolkata, West Bengal.
}

\section{ABSTRACT}

\section{BACKGROUND}

Image of anaesthesia and anaesthesiologist in the eyes of patients is variedly reported in literature and mostly poor in developing countries. We often realised this underestimation of our risky task, inadequate appreciation and recognition of our effort from patients. Hence, we put an endeavour to explore the existing perception among our patients in this rural region regarding our specialty and anaesthesiologist.

\section{MATERIALS AND METHODS}

This observational, paper-based questionnaire survey was carried out in the pre-anaesthetic checkup (PAC) clinic involving 101 patients scheduled to undergo elective surgery. The survey was carried out using structured interview based on the open-ended questionnaire consisting of 15 MCQ type questions. Data were mostly categorical data such as number of patients (percentage). Statistical comparison has been done between the favourable response (s) and all other responses taken together as unfavourable response (s).

\section{RESULTS}

About $44 \%$ of patients knew that anaesthesiologists are qualified doctors. Thirty percent had knowledge that anaesthesiologist has to be present after induction for continuation of the anaesthesia and for monitoring the vitals. About $10 \%$ patients are aware about the other roles of anaesthesiologists outside operating room. Regarding the risk related with anaesthesia and surgery, majority of patients (58\%) were not informed at all. A considerable proportion of patients (90\%) opined that pre-anaesthetic checkup is useful. Among the high literacy group, considerably higher proportions of patients have answered the favourable options.

\section{CONCLUSION}

The survey concludes that patients' perception about anaesthesia is poor. The patients also have insufficient knowledge about the exact role of an anaesthesiologist inside or outside the operating room.

\section{KEYWORDS}

Anaesthesia, Anaesthesiologist, Attitude, Knowledge, Patient Education, Perception, Pre-anaesthetic Check-up, Public Awareness.

HOW TO CITE THIS ARTICLE: Sarkar S, Mandal M, Chakrabarti P, et al. Survey of patients' attitude about anaesthesia and anaesthesiologist- a preliminary evaluation in a rural hospital of North Bengal. J. Evolution Med. Dent. Sci. 2017;6(51):3922-3928, DOI: $10.14260 /$ Jemds/2017/849

\section{BACKGROUND}

Anaesthesiology is one of the rapidly evolving disciplines of medical science that has made immense development in the recent past. Advancement in surgery and anaesthesia are going absolutely parallel to each other. Anaesthesiologists are playing a decisive role in patient management. In the last two decades, the role of anaesthesiologist has extended not only inside but also outside traditional operating room (OR) settings. An anaesthesiologist plays a very crucial role in intensive critical care units, trauma centres, pain clinics and as a member of resuscitation team all over the world.1

Financial or Other, Competing Interest: None.

Submission 20-05-2017, Peer Review 14-06-2017,

Acceptance 19-06-2017, Published 24-06-2017.

Corresponding Author:

Susanta Sarkar,

Flat No. B/2/2,

Himalaya Residency, Neli Sengupta Sarani,

Babupara, P. O. Siliguri District,

Darjeeling-734004, West Bengal, India.

E-mail: susantaanesth@yahoo.in

DOI: $10.14260 /$ jemds $/ 2017 / 849$
Preoperative patient evaluation is an invaluable task of an anaesthesiologist. It not only helps the anaesthetists to know their patients, choose appropriate anaesthetic technique and get important equipment ready but also helps educate the patient on what to expect and what will happen to the patient. This may help the patient to remain calm and comfortable during surgery. A good anaesthetist-patient relationship established during the preoperative visit may help to reduce patient's anxiety and might reduce the chance of budding of medicolegal issues. The other valuable role of anaesthesiologists such as giving medical advice to other specialties, teaching in medical institutions and doing research were not generally recognised and appreciated.

Although at present there is tremendous health care awareness in developed countries, the awareness among people regarding the specialty of anaesthesiology is not encouraging. The picture is further gloomy in the developing countries such as India. ${ }^{2}$ The public image is very poor as many people believe that an anaesthesiologist is not a medically qualified person. The widespread role of anaesthesiologists in short-term care, intensive care as well as in pain relief is not known to the public. ${ }^{3}$ 
An anaesthesiologist does not spend as much time with a patient as a surgeon does. He gets to talk with his patient only during his one or two preoperative visits. Hence, there is a widespread misconception amongst the public about the role of anaesthesiologists and their responsibilities inside or outside the OR.

Recognition of the anaesthesia profession as an independent specialty would encourage future recruits to take up the specialty. Lack of recognition and decreased appreciation of the role of the anaesthesiologist by the patient contributes to the frustration of the anaesthetic practitioner which in turn can lead to decrease in recruiting and retaining the staff in the discipline. ${ }^{4}$ With the changing health care environment and advancement in anaesthesiology, the patients and general public needs to be educated. ${ }^{5}$ Patients' knowledge and perception about anaesthesiology and the anaesthesiologist should be assessed before put forward of any suggestion. With this background, we conducted a study in an attempt to explore the patients' perception and knowledge regarding anaesthesiology and the role of anaesthesiologists.

\section{MATERIALS AND METHODS}

After approval by the Institute's Ethics Committee, the present observational paper-based questionnaire survey was conducted in a tertiary care hospital (Teaching institution) in North Bengal, over a span of six months (From October 2016 to March 2017). The study was carried out in the preanaesthetic checkup (PAC) clinic of the Department of Anaesthesiology with 101 patients scheduled to undergo elective surgery. Patients with age $<18$ years, severe medical illness, psychiatric illness, brain damage, difficulty with hearing, inability to speak, and those who were unwilling to participate were excluded from the study. Written informed consent has been obtained from all participants after reading a leaflet on this investigation. Study was purely verbal in nature. It was a structured interview based on the open-ended questionnaire. Interviews were carried out after PAC by a separate team of a few selected anaesthesiologists. The validity of questionnaire was verified by three experts in the field of anaesthesiology.

Apart from demographic data of patients (Age, gender, and educational level of the respondent) each patient was asked with a standardised questionnaire of 15 questions of MCQ type with options covering discrete facts and sometimes requiring a "yes," "no," "no idea" response. The set of questions aimed in assessing perceptions and knowledge of anaesthesia, importance of PAC and the exact role of anaesthesiologist inside the operating theatre. Questions pertaining to the risk of anaesthesia and surgery, as well as various roles of anaesthesiologist outside the OR were also asked. Patients' desire to know more information and his reaction to the interview was also noted.

Data collected from all respondents were entered in the Microsoft Excel sheet. The number of participants, their percentages of option selected for each question was calculated. Data were mostly categorical data such as number of patients (percentage). Statistical comparison has been done between the favourable response (s) and all other responses taken together as unfavourable response (s). Chi-square test has been done using Epi Calc 2000 (Brixton Health). $\mathrm{P}<0.05$ was considered as significant.

\section{RESULTS}

Altogether responses were obtained from 101 participants amongst which 49 (48.5\%) were male and 52 (51.5\%) were female. Literacy level was arbitrarily defined 'low' for those having up to standard VIII education and 'high' for those having more than that. Mean age of male and female patients were 39.2 and 37.8 , respectively (Table 1 ).

\section{Regarding the Qualification and the exact role of Anaesthesiologist}

Regarding the qualification of anaesthesiologist (Q1), about $44 \%$ of patients knew that anaesthesiologists are qualified doctors and out of those, relatively more number of females are aware about that. When asked about the source of this knowledge (Q2), majority answered that it was hearsay. Regarding the exact the nature of work done by the anaesthesiologist in the operating room, about 30\% had knowledge that an anaesthesiologist has to be present after induction for the continuation of the anaesthesia and for monitoring the vitals (Q3). Remaining 70\% of patients had either no idea or wrong idea. Although majority (47\%) had no idea about postoperative care personnel (Q4), more number of patients believed that they will be looked after in the postoperative period by surgeons than anaesthetists $34 \%$ versus $19 \%$, respectively). About $90 \%$ of patients had no idea about any other role of anaesthesiologists outside the OR (Q5). Out of the remaining $10 \%$ patients who answered that there is some role outside the $\mathrm{OR}$, around $6 \%$ said about duty in CCU and $3 \%$ in pain management. Only one patient mentioned about the role in painless delivery (Q6). (Table 2).

\section{Regarding the PAC and its Importance}

When asked about whether they are adequately informed about their surgery before this PAC (Q7), about $66 \%$ of the patients answered it as positive. Out of this $66 \%$, the female patients are more informed than the males (75\% vs. $57 \%$ ). Those who were not informed (34\%) before this PAC, about $50 \%$ achieved either full or partial information from this PAC (Q8). Thus, about $17 \%$ of total participants still remain 'not informed' even after the PAC.

When asked about the key person for declaring anaesthesia fitness for surgery (Q9), quite sufficient number of patients put credit to surgeons compared with anaesthesiologists (25\% vs. $37 \%$ ). Majority of patients (77\%) considered the PAC to be 'time consuming but useful' (Q10). Only $12 \%$ patients certified it to be 'quick service and useful'. Most of the patients (71\%) preferred one extra visit in the night before operation (Q11) to allay their anxiety.

Regarding the personnel who have informed them about the risk related with anaesthesia and surgery (Q12), majority of the patients (58\%) were not at all informed. Only $10 \%$ patients had been informed in the surgical OPD before this PAC and about 33\% have been informed during recent PAC. A major portion of the patients $(89 \%)$ had considered the process of laboratory 'investigations and referral to other departments' (Q13) to be essential for the safety and not as harassment. About $80 \%$ of the patients thought PAC to be essential for safe surgery (Q14) (Table 3). 


\begin{tabular}{|c|c|c|c|c|}
\hline \multirow{2}{*}{\multicolumn{2}{|c|}{ No. of Patients }} & \multirow{2}{*}{ Mean Age (Yrs.) } & \multicolumn{2}{|c|}{ Level of Education } \\
\hline & & & Low Literacy =up to class VIII & High Literacy >class VIII \\
\hline \multicolumn{2}{|r|}{ Total $n=101$} & 38.49 & $61(60.39 \%)$ & $40(39.60 \%)$ \\
\hline \multirow{2}{*}{ Gender } & Male, $n=49(48.51 \%)$ & 39.18 & $27(55.10 \%)$ & $22(44.90 \%)$ \\
\hline & Female, $\mathrm{n}=52$ (51.49\%) & 37.83 & $34(65.38 \%)$ & $18(34.62 \%)$ \\
\hline
\end{tabular}

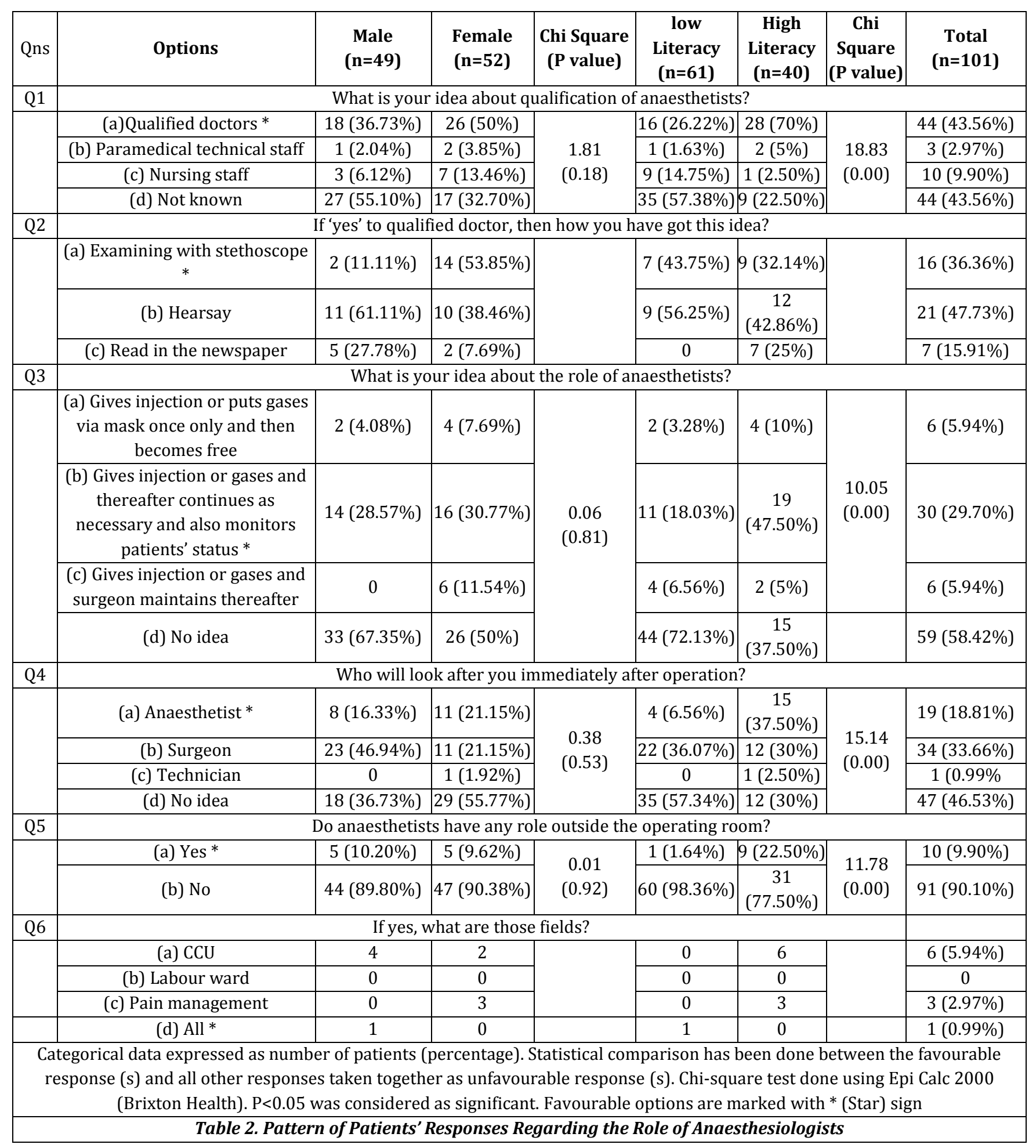




\begin{tabular}{|c|c|c|c|c|c|c|c|c|}
\hline Qns & Options & $\begin{array}{c}\text { Male } \\
(n=49)\end{array}$ & $\begin{array}{l}\text { Female } \\
(n=52)\end{array}$ & \begin{tabular}{|c} 
Chi \\
Square \\
(P value)
\end{tabular} & $\begin{array}{c}\text { Low } \\
\text { Literacy } \\
(n=61)\end{array}$ & $\begin{array}{c}\text { High } \\
\text { Literacy } \\
(n=40)\end{array}$ & \begin{tabular}{|c|} 
Chi \\
Square \\
(P value) \\
\end{tabular} & $\begin{array}{c}\text { Total } \\
(n=101)\end{array}$ \\
\hline Q7 & \multicolumn{8}{|c|}{ Have you been informed about specific surgery before this check-up (PAC)? } \\
\hline & (a)Yes * & $28((57.14 \%)$ & $39((75 \%)$ & 3.60 & $35(57.38 \%)$ & $32(80 \%)$ & \multirow{2}{*}{$\begin{array}{c}5.54 \\
(0.02)\end{array}$} & $67(66.33 \%)$ \\
\hline & (b) No & $21(42.86 \%)$ & $13(25 \%)$ & $(0.06)$ & $26(42.62 \%)$ & $8(20 \%)$ & & $34(33.66 \%)$ \\
\hline Q8 & \multicolumn{8}{|c|}{ If no, after this PAC, are you well informed about your operation besides the mode of anaesthesia? } \\
\hline & (a) Well informed & $3(14.29 \%)$ & $3(23.07 \%)$ & & $2(7.69 \%)$ & $4(50 \%)$ & & $6(17.65 \%)$ \\
\hline & (b) Partially informed & $1(4.76 \%)$ & $10(76.92 \%)$ & & $10(38.46 \%)$ & $1(12.50 \%)$ & & $11(32.35 \%)$ \\
\hline & (c) Not informed & $17(80.95 \%)$ & 0 & & $14(53.85 \%)$ & $3(37.50 \%)$ & & $17(50 \%)$ \\
\hline Q9 & \multicolumn{8}{|c|}{ Who will decide whether you are fit for operation? } \\
\hline & (a) Anaesthetist* & $20(40.82 \%)$ & $17(32.69 \%)$ & \multirow{4}{*}{$\begin{array}{c}0.72 \\
(0.40)\end{array}$} & $13(21.31 \%)$ & $24(60 \%)$ & \multirow{4}{*}{$\begin{array}{l}15.58 \\
(0.00)\end{array}$} & $37(36.63 \%)$ \\
\hline & (b) Surgeon & $10(20.41 \%)$ & $15(28.85 \%)$ & & $19(31.15 \%)$ & $6(15 \%)$ & & $25(24.75 \%)$ \\
\hline & (c) Nurses & 0 & 0 & & 0 & 0 & & 0 \\
\hline & (d) No idea & $19(38.78 \%)$ & $20(38.46 \%)$ & & $29(47.54 \%)$ & $10(25 \%)$ & & $39(38.61 \%)$ \\
\hline Q10 & \multicolumn{8}{|c|}{ What is your idea about the PAC regarding the time consumption and usefulness? } \\
\hline & $\begin{array}{l}\text { (a) Got quick service } \\
\text { and useful* }\end{array}$ & $4(8.16 \%)$ & $8(15.38 \%)$ & \multirow{3}{*}{$\begin{array}{c}2.23 \\
(0.14)\end{array}$} & $10(16.39 \%)$ & $2(5 \%)$ & \multirow{3}{*}{$\begin{array}{c}0.78 \\
(0.38)\end{array}$} & $12(11.88 \%)$ \\
\hline & $\begin{array}{l}\text { (b) Time consuming, } \\
\text { but useful * }\end{array}$ & $42(85.71 \%)$ & $36(69.23 \%)$ & & $43(70.49 \%)$ & $35(87.50 \%)$ & & $78(77.22 \%)$ \\
\hline & $\begin{array}{l}\text { (c) time consuming \& } \\
\text { not useful }\end{array}$ & $3(6.12 \%)$ & $8(15.38 \%)$ & & $8(13.11 \%)$ & $3(7.50 \%)$ & & $11(10.89 \%)$ \\
\hline Q11 & \multicolumn{8}{|c|}{ Do you think that one extra visit in the night befo } \\
\hline & (a) Yes * & $26(53.06 \%)$ & $46(88.46 \%)$ & 15.45 & $44(72.13 \%)$ & $28(70 \%)$ & \multirow{2}{*}{$\begin{array}{c}0.05 \\
(0.82)\end{array}$} & $72(71.28 \%)$ \\
\hline & (b) No & $23(46.94 \%)$ & $6(11.54 \%)$ & $(0.00)$ & $17(27.88 \%)$ & $12(30 \%)$ & & $29(28.71 \%)$ \\
\hline Q12 & \multicolumn{8}{|c|}{ Have you been told about the risk of anaesthesia and surgery by this time? Where and by whom? } \\
\hline & $\begin{array}{l}\text { (a) before PAC, by } \\
\text { surgeon * }\end{array}$ & $3(6.12 \%)$ & $7(13.46 \%)$ & \multirow{3}{*}{$\begin{array}{l}35.81 \\
(0.00)\end{array}$} & $7(11.48 \%)$ & $3(7.50 \%)$ & \multirow{3}{*}{$\begin{array}{c}0.70 \\
(0.40)\end{array}$} & $10(9.90 \%)$ \\
\hline & $\begin{array}{c}\text { (b) during this PAC, by } \\
\text { the anaesthetist * }\end{array}$ & $3(6.12 \%)$ & $30(57.69 \%)$ & & $21(34.43 \%)$ & $12(30 \%)$ & & $33(32.67 \%)$ \\
\hline & $\begin{array}{c}\text { (c) nothing told about } \\
\text { the risks }\end{array}$ & $43(87.76 \%)$ & $15(28.85 \%)$ & & $33(54.10 \%)$ & $25(62.50 \%)$ & & $58(57.42 \%)$ \\
\hline Q13 & \multicolumn{8}{|c|}{ Do you think all these laboratory investigations and referral to other departments are 'harassment' for you? } \\
\hline & (a) Yes, it is harassment & $3(6.12 \%)$ & $7(13.46 \%)$ & \multirow{3}{*}{$\begin{array}{c}2.23 \\
(0.14)\end{array}$} & $6(9.84 \%)$ & $4(10 \%)$ & \multirow{3}{*}{$\begin{array}{c}0.05 \\
(0.82)\end{array}$} & $10(9.90 \%)$ \\
\hline & $\begin{array}{c}\text { (b) No, it is essential for } \\
\text { our safety * }\end{array}$ & $46(93.88 \%)$ & $44(84.61 \%)$ & & $54(88.52 \%)$ & $36(90 \%)$ & & $90(89.10 \%)$ \\
\hline & (c) No idea & 0 & $1(1.92 \%)$ & & $1(1.64 \%)$ & 0 & & $1(0.99 \%)$ \\
\hline Q14 & \multicolumn{8}{|c|}{ Do you think that PAC is essential for a safe surgery? } \\
\hline & $\begin{array}{l}\text { (a)It is of course } \\
\text { essential * }\end{array}$ & $42(85.71 \%)$ & $39(75 \%)$ & \multirow{3}{*}{$\begin{array}{c}1.82 \\
(0.18)\end{array}$} & $47(77.05 \%)$ & $34(85 \%)$ & \multirow{3}{*}{$\begin{array}{c}0.96 \\
(0.33)\end{array}$} & $81(80.20 \%)$ \\
\hline & $\begin{array}{c}\text { (b)It is needed, but not } \\
\text { essential }\end{array}$ & $6(12.24 \%)$ & $7(13.46 \%)$ & & $8(13.11 \%)$ & $5(12.50 \%)$ & & $13(12.87 \%)$ \\
\hline & (c)No idea at all & $1(6.12 \%)$ & $6(11.54 \%)$ & & $6(9.84 \%)$ & $1(2.50 \%)$ & & $7(6.93 \%)$ \\
\hline Q15 & \multicolumn{8}{|c|}{ Do you have any other queries about anaesthesia and surgery? } \\
\hline & (a) Yes & $8(16.33 \%)$ & $9(17.30 \%)$ & \multirow{2}{*}{$\begin{array}{c}0.02 \\
(0.90)\end{array}$} & $7(11.48 \%)$ & $10(25 \%)$ & \multirow{2}{*}{$\begin{array}{c}3.16 \\
(0.08)\end{array}$} & $17(16.83 \%)$ \\
\hline & (b) No* & $41(83.67 \%)$ & $43(82.69 \%)$ & & $54(88.52 \%)$ & $30(75 \%)$ & & $84(83.17 \%)$ \\
\hline $\mathrm{Ca}$ & $\begin{array}{r}\text { rical data expressed a } \\
\text { (s) and all other resp } \\
\text { Health). } \mathrm{P}<0.0\end{array}$ & $\begin{array}{l}\text { mber of patie } \\
\text { es taken toget } \\
\text { as considered }\end{array}$ & $\begin{array}{l}\text { (percentage) } \\
\text { as unfavour } \\
\text { significant. F }\end{array}$ & $\begin{array}{l}\text { Statistica } \\
\text { le respo } \\
\text { jourable }\end{array}$ & $\begin{array}{l}\text { comparison } \\
\text { ses. Chi-squa } \\
\text { ptions are m }\end{array}$ & $\begin{array}{l}\text { been done } \\
\text { cest done u } \\
\text { ed with * }\end{array}$ & $\begin{array}{l}\text { tween the } \\
\text { EpiCalc } 2 \\
\text { c) sign. }\end{array}$ & $\begin{array}{l}\text { favourable } \\
000 \text { (Brixton }\end{array}$ \\
\hline
\end{tabular}

\section{DISCUSSION}

The present survey was carried out to explore the patients' existing perceptions about anaesthesiologist and anaesthesiology in this rural area. The discipline Anaesthesiology is being misconceived as a 'behind the screen' specialty ${ }^{6}$ with insufficient appreciation from the patients and family members while the anaesthesiologists have to take a major blunt of risks associated with anaesthesia and surgery. The patients often do not recall the name of anaesthesiologists while remembering the details of their surgeon. One reason may be that the patients first consult their surgeon and thereafter as per surgeon's workup for the surgery they are referred to the anaesthesiologist. Often the anaesthesiologists assessing preoperatively and the performing anaesthesiologist in operating room are different persons. Moreover, the interview with patients is usually for a brief period and does not put an impression. The image of the anaesthesiologist is poor and many patients do not know that 
anaesthesiologist is a medically qualified physician. ${ }^{6}$ Often they consider the anaesthesiologists as mere a technician or assistant of their surgeon. The public often nurture the wrong concept that the anaesthesiologists just administer a calculated dose of injection or certain amount of gases to put the patients asleep for a certain period of time. Often, they have a notion that if this dose becomes high the patients do not wake up and succumb. The continuous process of anaesthesia along with monitoring of vitals is not perceived by most of the patients.

The present study finds that less than a half (44\%) of the patients know that anaesthesiologists are doctors. Previous studies have reported various proportions of patients having the knowledge that anaesthesiologists are doctors. The proportions of aware patients starting from 30-40\%,1,2,7,8 40 50\%, ${ }^{\text {,-11 }} 50-60 \%,{ }^{\mathbf{6}, 12-17} 75 \%{ }^{\mathbf{1 8}, 19}$ to high level $\sim 80 \%{ }^{\mathbf{2 0 - 2 2}}$ and very high level (90\% and above), ${ }^{23-25}$ all have been documented in the literature. A recent survey even reports quite low (19\%) proportion of respondents knowing that anaesthetists should administer anaesthetics and half of this cohort knew that the anaesthetist is a qualified doctor. ${ }^{26}$

Regarding the source of this knowledge (Q2), majority of patients answered that it was from hearsay. Social campaign and existing baseline awareness of public is thus important to transmit the baseline education to a patient about anaesthesia and anaesthesiologists.

Regarding the exact nature of work done by the anaesthesiologist, the majority (About 60\%) had no idea and only one third of them know correctly that the anaesthesiologists continuously perform the process of anaesthesia and monitor the patients' vitals. However, previous studies have reported a greater portion of patients $\left(60 \%{ }^{1}\right.$ and $\left.89 \%{ }^{27}\right)$ recognising the role of an anaesthesiologist in monitoring vitals of patients during surgery. However, a recent study observed that $45.5 \%$ of patients considered anaesthesia to be mere 'putting people to sleep and waking them up' and about one fifth $(\sim 22 \%)$ said 'it involves the preoperative evaluation and perioperative management'.28

In the present survey, in reply to asking 'who would look after in the postoperative period', majority had either no idea $(47 \%)$ or believed that they will be looked after in the postoperative period by surgeons (34\%) compared with anaesthetists (19\%). A recent study ${ }^{29}$ in a developing country among the paramedical staff reports that $71 \%$ respondents knew their anaesthesiologists to perform something and 23\% believed that anaesthesiologists would manage pain. However, for the management of postoperative complications, respondents put confidence mostly to surgeons, somewhat to other physician (77\%, and $18 \%$ of respondents) with no mention of anaesthesiologists. ${ }^{29}$

In the present survey, only $10 \%$ of the patients knew about the roles of anaesthesiologist outside the OR. Out of these, around $6 \%$ knew about duty in CCU and 3\% were aware of role in pain management. Only one patient mentioned about the role in painless delivery. The role of anaesthesiologists outside the OR was reported in previous studies as around 15$30 \% .1,20,30$ A recent study ${ }^{22}$ reports that about $65 \%$ patients believe that an anaesthetist can manage all types of pain. Prasad \& Suresh 18 also found that $68 \%$ of their observed patients knew the role of anaesthesiologists in pain management and a major portion $(72.5 \%)$ knew about painless labour. In our institute although the pain clinic and
CCU are running for last 5 years, poor response rate regarding the role outside the $\mathrm{OR}$ indicates that these roles are perceived poorly by the patients. Hence, an endeavour should be given by the anaesthesiologists in providing more information voluntarily regarding an anaesthesiologist's various roles outside the OR.

Also, it has to be noted that in the current survey among the high literacy group, considerably higher proportion of patients have answered the favourable options, thus signifying that with higher literacy people are more aware of the qualification, exact role of anaesthesiologist inside and outside of OR. Likewise, with higher literacy we have received considerable favourable response with the questions about who is the key person about deciding fitness for surgery (Q9) and explaining risks of anaesthesia and surgery (Q12). Previous studies, $\mathbf{6 , 2 6 3 1}$ also report that patients with higher level of education have a better knowledge about the anaesthesiologist's role.

In the present study, considerable number of female patients are aware of the risks of anaesthesia (Q12). Comparable responses between male and female patients were observed with other questions between male and female responders. In a recent study, Abdullah S. Alqefari et $\mathrm{al}^{22}$ also found no differences while considerable association between female gender and better knowledge was observed by other researcher. ${ }^{11}$

In the present survey about one third patients are not adequately informed about their particular nature of surgery before PAC and $50 \%$ of those remained so even after the PAC. This implies that further effort and time should be devoted to provide adequate information regarding the nature of anaesthesia and surgery. Regarding the key person for declaring anaesthesia fitness, quite sufficient number of patients put credit to surgeons compared with anaesthesiologists (25\% vs $37 \%$ ). This might result from the preliminary investigation work-up by surgeons and their subsequent continual efforts of referral to PAC clinic and other departments for preparing their patients.

Among the patients who considered PAC to be useful, the majority of patients $(77 \%)$ considered the PAC to be 'time consuming but useful' whereas only $12 \%$ patients certified it to be 'quick service and useful'. Hence, proper allocation of human resource and avoidance of unnecessary referral has to be accomplished to reduce the queue time and also to expedite necessary investigations.

In the current survey, majority of patients considered PAC workup to be useful and inclined to have an extra visit by the anaesthesiologist before surgery to allay their anxiety. Mushin $W^{32}$ nicely commented that "A pre-operative visit is often as effective as an injection of morphine". Morphine was used almost routinely for preoperative sedation, pre-emptive analgesia and relief of anxiety in the past. The preoperative anxiety in adults ranges from $11-80 \% .^{33}$ Common concern about anaesthesia remains to be non-arousal from anaesthesia, wake-up (Awareness) during anaesthesia, pain and postoperative nausea and vomiting. ${ }^{34,35}$ The preanaesthetic consultation, if effectively performed, plays an important role in educating patients and thereby curtailing this anxiety. ${ }^{5}$

In the current survey, lesser patients were aware of the risk of anaesthesia and surgery in the surgery OPD compared with PAC (10\% versus 33\%, respectively). This may reflect 
that anaesthesiologists are more concern about informing the patients about the risks related with perioperative events. Although the majority are not informed at all, thus suggesting more rigorous effort and attention should be paid regarding clear description and disclosure of risks during taking informed consent.

In the present survey, the majority of patients (89\%) had considered the process of laboratory 'investigations and referral to other departments' to be essential for their safety and about $80 \%$ of the patients thought PAC to be essential for their safety during anaesthesia and surgery (Q13 and Q14). In a Caribbean study, majority of patients expressed that attending PAC process is worthwhile. ${ }^{6}$

The question may arise how much this public image about the anaesthesiologist is really important! Hall IA \& Earlam C ${ }^{36}$ opined that anaesthesiologists 'should not be upset' with the 'widespread ignorance' and advised to swallow the pride and continue rendering services as 'silent heroes'. However, the opposite views do exist where Ross $\mathrm{DG}^{37}$ proposed that anaesthesiologists should 'not start posing as silent heroes' and rather instigated to bear a low threshold for becoming vocal whenever the situation demands. The author believed that with the increase in appreciation by public, the anaesthesiologist's ability would increase to influence the provision of suitable resources within the area of their expertise. The lack of recognition can simply affect the selfesteem of the anaesthesiologists and help budding job dissatisfaction. ${ }^{29}$ This will hamper the performance and thereby the output by the anaesthesiologists in the long run.

Despite the booming role of anaesthesiologists, they are often underestimated not only by patients and public but also by colleagues and administrators. Many of our medical and surgical colleagues consider the process of anaesthesia as mere a procedure and not as a patient-oriented clinical work. Often administrators are unaware about the dimensions of an anaesthesiologist's capabilities and believe that the anaesthesiologist can be replaced by other professionals. ${ }^{38}$ The network media should emphasise the role of anaesthesia team in the successful outcome of surgery. ${ }^{31}$

Lack of communication from the side of anaesthesiologists may attribute to the current unfavourable scenario regarding patients' knowledge and perception about anaesthesia. ${ }^{39}$ Effective patient education warrants good communication skills, due consideration to adult learning and teaching principles, devoting more time during PAC, and selecting suitable media to meet the individual patient's needs. ${ }^{40}$ The use of relevant media, together with reinforcement by the consulting anaesthesiologist, may be able to increase patient confidence and compliance with perioperative events. Patient satisfaction is a complex psychological phenomenon and should be assessed with reliable and valid questionnaires. ${ }^{41}$ The magnitude of preparing a patient preoperatively with the use of video seems to depend on the style of presentation of such a video. ${ }^{42}$

There are limitations of our survey. It was a preliminary effort involving less number of patients. Hence, the inference of this observation may not have sufficient external validity. However, we consider that it has thrown some light to the existing problems. Further studies would be beneficial involving large number of patients, and separate evaluation regarding the status of the discipline and image of the anaesthesiologists amongst the administrators, paramedical personnel, etc. remains to be future scopes.

\section{CONCLUSION}

In this survey, it has been observed that patients' knowledge and perception about anaesthesia is poor. Also, patients are not sufficiently aware about the exact role of an anaesthesiologist in OR and outside the OR. It has to be emphasised that anaesthesiologists should express their activities more to their patients, make use of the media and internet and strive towards providing high quality perioperative care which will help improving their image in the eyes of the public. A close anaesthesiologist-patient contact prior to surgery is a fundamental component of high standard of practice and this can only be achieved by devoting adequate time with patients. Achieving adequate awareness among the public regarding anaesthesia and anaesthesiologists will decide the future image of our specialty.

\section{ACKNOWLEDGMENT}

We extend our sincere thanks to Dr. Abhijit Mukherjee, Assistant Professor, Department of Community Medicine, North Bengal Medical College, for his valuable contribution in statistical analysis.

\section{REFERENCES}

[1] Swinhoe CF, Groves ER. Patients' knowledge of anaesthetic practice and the role of anaesthetists. Anaesthesia 1994;49(2):165-6.

[2] Jathar D, Shinde VS, Patel RD, et al. A study of patients' perception about knowledge of anaesthesia \& anaesthesiologist. Indian J Anaesth 2002;46(1):26-30.

[3] Simini B. Anaesthetist: the wrong name for the right doctor. Lancet 2000;355(9218):1892.

[4] Hofer CK, Ganter MT, Furrer L, et al. Patients' needs and expectations regarding anaesthesia. A survey on the preanaesthetic visit of patients and anaesthesiologists Anaesthesist 2004;53(11):1061-8.

[5] Klafta JM, Roizen MF. Current understanding of patients' attitudes toward and preparation for anesthesia: a review. Anesth Analg 1996;83(6):1314-21.

[6] Hariharan S, Merritt-Charles L, Chen D. Patient perception of the role of anaesthesiologists: a perspective from the Caribbean. J Clin Anesth 2006;18(7):504-9.

[7] Irwin MG, Fung SK, Tivey S. Patient's knowledge and attitudes towards anaesthesia and anaesthetics in Hong Kong. Hong Kong Med J 1998;4(1):16-22.

[8] Pandya K, Mehta KH, Patel KD. Awareness regarding anaesthesiology and anaesthesiologists among general population in developing country - a cross sectional survey. Ntl J Community Med 2016;7(6):515-8.

[9] Naithani U, Purohit D, Bajaj P. Public awareness about anaesthesia and anaesthesiologist: a survey. Indian J Anaesth 2007;51(5):420-6.

[10] Mathur SK, Dube SK, Jain S. Knowledge about anaesthesia and anaesthesiologist amongst general population in India. Indian J Anaesth 2009;53(2):17986.

[11] Naod B, Admasu W, Ahmed Y. Patient's knowledge and attitude towards anesthesia in Tikur Anbesa Specialized Hospital. Int J Anesth Res 2016;4(5):229-35. 
[12] Khan FA, Hassan S, Zaidi A. Patients view of the anaesthetist in a developing country. J Pak Med Assoc 1999;49(1):4-7.

[13] Singla D, Mangla M. Patient's knowledge and perception of preanesthesia check-up in rural India. Anesth Essays Res 2015;9(3):331-6.

[14] Baaj J, Takrouri MSM, Hussein BM, et al. Saudi patient's knowledge and attitude toward anesthesia and anaesthesiologists. A prospective cross-sectional interview questionnaire. Middle East J Anesthesiol 2006;18(4):679-91.

[15] Chew ST, Tan T, Tan SS, et al. A survey of patients' knowledge of anaesthesia and perioperative care. Singapore Med J 1998;39(9):399-402.

[16] Sagun A, Birbicer H, Yapici G. Patients', who applied to the anesthesia clinic, perceptions and knowledge about anesthesia in Turkiye. Saudi J Anaesth 2013;7(2):170-4.

[17] Bhandary A, Pallath NM, Ramakrishna M, et al. A survey on patients' awareness about anesthesia and anesthesiologist. Indian Journal of Clinical Anaesthesia 2016;3(2):196-206.

[18] Prasad CGS, Suresh G. A survey on public awareness about the role of anesthesiologists. Ain-Shams J Anaesthesiol 2014;7(3):456-9.

[19] Lee JJ, Lee NH, Park CM, et al. Public awareness about the specialty of anesthesiology and the role of anesthesiologists: a national survey. Korean J Anesthesiol 2014;66(1):12-17.

[20] Ahsan-Ul-Haq M, Azim W, Mubeen M. A survey of patients' awareness about the perioperative role of anaesthetists. Biomedica 2004;20:5-9.

[21] Acosta-Martínez J, Guerrero-Domínguez R, LópezHerrera-Rodríguez D, et al. The anaesthetist's role from the patient's perspective. Rev Colomb Anestesiol 2016;44(2):121-7.

[22] Alqefari AS, Alyami AA, Almowald TM, et al. A survey on public awareness about the role of anesthesiologists. Int J Adv Res 2017; (2):1901-6.

[23] Kindler CH, Harms C, Alber C. The patient's perception of the anaesthetist in a Swiss university hospital. Anaesthetist 2002;51(11):890-6.

[24] Calman LM, Mihalache A, Evron S, et al. Current understanding of the patient's attitude toward the anesthetist's role and practice in Israel: effect of the patient's experience. J Clin Anesth 2003;15(6):451-4.

[25] Tohmo H, Palve H, Illman H. The work, duties and prestige of Finnish anesthesiologists: patients' view. Acta Anaesthesiol Scand 2003;47(6):664-6.

[26] Eyelade OR, Akinyemi JO, Adewole IF. Patients' perception and knowledge of anaesthesia and anaesthetists -- a questionnaire survey. S Afr J Anaesthesiol Analg 2010;16(4):28-31.
[27] Herman CR. An appraisal of the anaesthetist-patient relationship. Anaesthesia 1978;33(1):45-8.

[28] Djagbletey R, Aryee G, Essuman R, et al. Patients' knowledge and perception of anaesthesia and the anaesthetist at a tertiary health care facility in Ghana. Southern African Journal of Anaesthesia and Analgesia 2017;23(1):11-6.

[29] Bhattarai B, Kandel S, Adhikari N. Perception about the role of anesthesia and anesthesiologist among the paramedical staffs: perspective from a medical college in Nepal. Kathmandu Univ Med J (KUMJ) 2012;10(38): 51-4.

[30] Uma BR, Hanji AS. Anaesthesia and anaesthesiologists: how famous are we among the general population? a survey. J Clin Diagn Res 2013;7(12):2898-900.

[31] Hiremath DA. Awareness about anesthesia and anesthesiologist among the paramedical staffs of SN medical college, Bagalkot (Karnataka). Journal of Evolution of Medical and Dental Sciences 2013;2(42): 8042-7.

[32] Mushin WW. Administration of drugs before anaesthesia. Br Med J 1960;1(5185):1558-60.

[33] Maranets I, Kain ZN. Preoperative anxiety and intraoperative anesthetic requirements. Anesth Analg 1999;89(6):1346-51.

[34] Matthey P, Finucane BT, Finegan BA. The attitude of the general public towards preoperative assessment and risks associated with general anesthesia. Can J Anaesth 2001;48(4):333-9.

[35] Chan CS, Molassiotis A. The effects of an educational programme on the anxiety and satisfaction level of parents having parent present induction and visitation in a postanesthesia care unit. Paediatr Anaesth 2002;12(2):131-9.

[36] Hall IA, Earlam C. They are not proper doctors, are they? Anaesthesia 1995;50(1):87.

[37] Ross DG. They are not proper doctors, are they? Anaesthesia 1995;50(6):577.

[38] Deutschman CS, Traber KB. Evolution of anesthesiology. Anesthesiology 1996;85(1):1-3.

[39] Singh PM, Kumar A, Trikha A. Rural perspective about anesthesia and anaesthesiologist: A cross-sectional study. J Anesthesiol Clin pharmcol 2013;29(2):228-34.

[40] Phillips LD. Patient education. Understanding the process to maximize time and outcomes. J Intraven Nurs 1999;22(1):19-35.

[41] Lee A, Chui PT, Gin T. Educating patients about anesthesia: a systematic review of randomized controlled trials of media-based interventions. Anesth Analg 2003;96(5):1424-31.

[42] Roth-Isigkeit A, Ocklitz E, Bruckner S, et al. Development and evaluation of a video program for presentation prior to elective cardiac surgery. Acta Anaesthesiol Scand 2002;46(4):415-23. 